\title{
Commuting with a Plan: How Goal-Directed Prospection Can Offset the Strain of Commuting
}

\section{Citation}

Jachimowicz, Jon M., Julia J. Lee, Bradley R. Staats, Jochen I. Menges, and Francesca Gino. "Commuting with a Plan: How Goal-Directed Prospection Can Offset the Strain of Commuting." Harvard Business School Working Paper, No. 16-077, January 2016.

\section{Permanent link}

http://nrs.harvard.edu/urn-3:HUL.InstRepos:25558708

\section{Terms of Use}

This article was downloaded from Harvard University's DASH repository, and is made available under the terms and conditions applicable to Open Access Policy Articles, as set forth at http:// nrs.harvard.edu/urn-3:HUL.InstRepos:dash.current.terms-of-use\#OAP

\section{Share Your Story}

The Harvard community has made this article openly available.

Please share how this access benefits you. Submit a story.

Accessibility 


\section{Commuting with a Plan: How Goal- Directed Prospection Can Offset the Strain of Commuting}

Jon M. Jachimowicz

Bradley R. Staats

Francesca Gino
Julia J. Lee

Jochen I. Menges

Working Paper 16-077 


\section{Commuting with a Plan: How Goal- Directed Prospection Can Offset the Strain of Commuting}

Jon M. Jachimowicz

Columbia Business School

Bradley R. Staats

University of North Carolina at Chapel Hill

\section{Francesca Gino}

Harvard Business School

\author{
Julia J. Lee \\ Ross School of Business, University of Michigan \\ Jochen I. Menges \\ WHU - Otto Beisheim School of Management
}

Working Paper 16-077 


\title{
Commuting with a Plan:
}

How Goal-Directed Prospection Can Offset the Strain of Commuting

\author{
*Jon M. Jachimowicz \\ Columbia Business School \\ jmj2183@columbia.edu \\ *Julia J. Lee \\ Ross School of Business, University of Michigan \\ jooalee@umich.edu \\ Bradley R. Staats \\ University of North Carolina at Chapel Hill \\ bstaats@unc.edu \\ Jochen I. Menges \\ WHU - Otto Beisheim School of Management \\ jochen.menges@whu.edu \\ Francesca Gino \\ Harvard Business School \\ fgino@hbs.edu \\ * denotes equal authorship
}

Corresponding Author:

Jon M. Jachimowicz

Uris Hall, Office 7-I

Columbia Business School

3022 Broadway

New York City, NY 10027

Phone: 646-647-5341 


\section{ACKNOWLEDGMENTS}

We thank DigitasLBi (John Monks) and Yomp (Ronan Carter) for their generous help in setting up the field studies, and Ceylan Oymak, Lauren Tassone, and Greg Gozzo for excellent research assistance. This research was in part funded by a Cambridge Judge Business School small grant awarded to the first author, Harvard Business School, and The Wharton School. 


\title{
Commuting with a Plan:
}

\section{How Goal-Directed Prospection Can Offset the Strain of Commuting}

\begin{abstract}
To get to work, employees need to commute. Across the globe, the average commute is 38 minutes each way per day. It is well known that longer commutes have negative effects on employees' well-being and job-related outcomes. Yet, commuting may not similarly affect all employees, since some of them may naturally engage in behaviors to offset the negative effects of longer commutes. Drawing on psychological research on self-control, we theorize how engaging in future-oriented thinking about the tasks to complete during the workday (i.e., goaldirected prospection) while commuting to work influences work outcomes. Across two field studies and one field experiment, we find that individuals higher in trait self-control are less likely to report negative effects of longer commutes. While commuting, individuals with higher trait self-control engage in goal-directed prospection, partially offsetting the strain of commuting. In a field experiment, individuals asked to engage in goal-directed prospecting during commuting reported higher levels of job satisfaction and lower levels of emotional exhaustion. Although commuting is typically seen as the least desirable part of an employee's day, our theory and results point to the benefits of viewing it as a useful time period to engage in goal-directed prospection.
\end{abstract}

Keywords: Commuting, Prospection, Job Satisfaction, Emotional Exhaustion, Self-Control 
Commuting is part of everyday life. Because home and office are often in separate locations, most employees face commutes every workday. Considering the average global commute is about 38 minutes in length each way (Rampell, 2011), an average commuter can expect to spend almost 300 hours traveling between work and home over the course of an entire year, more than $10 \%$ of total working time (OECD, 2014). Although commute time is related to work - without work, there is no need to commute - commuting is typically unpaid, and rarely included when calculating work time (BBC, 2015). And commutes are getting longer: for example, a recent study finds that the distance between employees and their workplaces in America has been steadily growing from 2000 to 2012 (Kneebone \& Holmes, 2015).

Despite being so common, people generally do not enjoy commuting. Employees' assessments of their most and least favorite activities vary greatly, and yet commuting is the most commonly mentioned least desirable time period of the day. In a survey conducted by Kahneman and Krueger (2006), for instance, respondents identified the morning journey between work and home as their least enjoyable activity, closely followed by the evening commute as third worst. Commuting is not only simply disliked, but it has been shown to lead to negative consequences for people. Lengthy commutes are associated with lower levels of subjective well-being (Stutzer \& Frey, 2008), higher separation rates amongst couples (Sandow, 2014) and greater levels of stress (Gottholmseder, Nowotny, Pruckner, \& Theurl, 2009; Novaco, Stokols, \& Milanesi, 1990). Longer commutes thus lead to outcomes that may influence people's attitudes and behaviors on the job - as lower well-being and greater stress have been found to reliably predict job satisfaction (Gaines \& Jermier, 1983) and emotional exhaustion (Fox, Dwyer, \& Ganster, 1993; Packard \& Motowidlo, 1987). In addition, longer commutes directly affect work-related outcomes, as commuting longer distances to work in the morning is 
positively correlated with lateness (Leigh \& Lust, 1988) and absenteeism (Van Ommeren \& Gutierrez-i-Puigarnau, 2011).

Despite the evidence regarding the harm that lengthy commutes pose on one's subjective well-being and work-related outcomes, little work has examined whether this relationship holds equally for all employees. This omission seems important as it may help scholars identify ways employees can approach commuting differently in order to offset its negative consequences. For example, some employees not only do not experience commuting as a negative time, but instead view commuting as a useful time period to think about work (Kluger, 1998) - a welcome opportunity rather than a chore or waste of time. Although Kluger (1998)'s work suggests that people may experience the effect of lengthy commutes differently, we know very little about which individual-level factors theoretically identify these classes of individuals. Beyond identifying who is less likely to suffer lower well-being from longer commutes, it is also unclear what those individuals do to offset longer commutes.

We propose that employees differ in what they think about while commuting as they are relatively free in choosing the thoughts they engage in during the time period spent commuting. What employees think about during their commute is likely to play an important role in determining work-related outcomes. To shed insight into the relationship between commuting and work-related outcomes, we draw on psychological research on self-control and conceptualize daily commuting as a self-control trade-off. In the domain of self-control, short-term temptations are pitted against the achievement of long-term goals (Baumeister, Bratslavsky, Muraven, \& Tice, 1998; Metcalfe \& Mischel, 1999). When commuting, employees have two choices, guided by their lay assumptions: if employees view commuting as a chore to endure, they are likely to strive toward engaging in an inherently pleasurable activity, such as reading a book, listening to 
music, or day-dreaming - thus giving in to short-term temptations to counter adverse feelings. If, in contrast, they view commuting as an opportunity to plan, they may use their free time to engage in future-oriented thoughts (e.g., how to organize and structure their work-day ahead) thus expending effort that likely proves beneficial later. Commuting therefore presents employees with a trade-off that is reminiscent of typical self-control dilemma. Notably, some individuals display a higher propensity to consistently choose long-term beneficial options in the face of short-term temptations; these individuals are high in trait self-control (Hofmann, Luhmann, Fisher, Vohs, \& Baumeister, 2014). Thus we propose that employees with higher levels of trait self-control are more likely to engage in goal-directed prospection during their commute, which is likely to offset the negative effects of lengthy morning commutes on job satisfaction and emotional exhaustion.

Our contributions are three-fold: First, we challenge the widespread assumption that lengthy commutes are bad for job-related outcomes for all employees. Instead, we conceptualize commuting time as a self-control trade-off, and find an individual difference in trait self-control as a critical moderator between the length of commute and job-related outcomes. Second, we advance the literature on boundary work (Ashforth, Kreiner, \& Fugate, 2000). Being a time period where employees are neither at home, nor at work, commuting serves as a transitional period between home- and work-related roles. Our work refines the theory on boundary work by identifying how a specific type of future-oriented thinking - goal-directed prospection - as a rite of role transition offsets some of the negative effects of daily commutes. Third, we extend the literature on work recovery by arguing that engaging in goal-directed prospection prior to work can increase job satisfaction and decrease emotional exhaustion, while the past literature has primarily focused on how individuals recover after or during their work day (Sonnentag, 2012; 
Trougakos \& Hideg, 2009). By focusing on the commute to work, rather than on the commute back from work, we shed light on how employees can turn the daily hassle of commuting into a meaningful activity that serves as a good start of the workday.

\section{THEORY DEVELOPMENT}

\section{Commuting as a Rite of Crossing Role Boundaries}

Besides being a means of transportation from home to work and back, commutes are also a unique time period when employees are neither at work, nor at home. Commuting, by nature of standing in the middle between work and home, is therefore a time period that differs from other time periods, and can be viewed as a suitable time period to engage in activities and thoughts employees do not usually have the opportunity to engage in. As one cardiologist, quoted in Yalof (1988: 84), details: “[...] That's one of the therapeutic things about having a long drive home. If I needed only five minutes to get home, I might spend a good deal more time thinking about things $[\ldots]$.” Lengthy commutes could give individuals an opportunity to relax and think, and thus reduce stress.

One can understand the interface between work and home as two domains demarcated by a boundary (Nippert-Eng, 1996). When this boundary is weakened, work seeps into home, and vice versa - sometimes with negative consequences. Although this spillover can be positive at

times, researchers have primarily been concerned with negative spillover that occurs when the demands of work and home compete for employees' time, energy, and attention (Small \& Riley, 1990). Trying to balance competing roles between work and home can lead to negative wellbeing (Mennino, Rubin, \& Brayfield, 2005; Schieman, McBrier, \& Gundy, 2003). Far from being passive recipients of such conflicts, however, employees can engage in boundary work that 
seeks to strengthen the demarcation between work and home, ultimately leading to positive outcomes (Bulger, Matthews, \& Hoffman, 2007).

One possible use of commuting is a suitable time period for boundary work to occur. As theorized by Ashforth et al. (2000), when employees commute to work, they tend to have a high degree of role segmentation between the domains of work and home. Even though a majority of employees tend to view commuting mainly as a source of frustration (Kahneman \& Krueger, 2006), commuting can also serve as a rite of passage, which facilitates movement of employees from one role to another (Ashforth et al., 2000; Richter, 1990; van Gennep, 1960). According to Van Gennep (1960), rites of passage can include three types: separation (facilitating role exit), transition (facilitating psychological and physical movement), and incorporation (facilitating role entry). Morning commutes, in particular, can serve as a distinct opportunity to provide a buffer between role identities as it serves to separate employees physically and psychologically from home and allows them to transition between distinctive role identities (Hall, 1990); facilitating role exit (leaving home), transition (transport to/from work) and role entry (arriving at work).

\section{Conceptualizing Morning Commute Activities as a Self-Control Trade-off}

When commuting to work, employees have two choices. They can either extend their non-work time by engaging in activities that are not work-related, such as listening to music or reading. Such activities are likely to help with separation and transition, and to create a mental buffer between role identities. Or, employees can enter work time by planning or reflecting on activities that relate to the accomplishment of work-related goals, thus facilitating incorporation. This suggests that activities that people engage in during the morning commutes create a tradeoff between short-term and long-term. That is, individuals are faced with a choice between 
engaging in instantly-gratifying non-work activities (such as relaxation) and engaging in effortful work-related activities that are not instantly gratifying, but bring longer-term benefits (such as prospection). For example, Olsson et al. (2013) suggest that some employees may engage in social or entertainment activities to increase positive affect during longer commutes, thus choosing instantly-gratifying activities over reaping longer-term benefits.

Conceptualizing one's choice of activities during morning commutes as a self-control trade-off raises a possibility that individuals may differ in their tendency to choose one option over the other. A wealth of previous psychological research has highlighted that some individuals are consistently better at choosing the long-term over the short-term option, dubbed in being high in trait self-control (Schmeichel \& Zell, 2007). Some people have better selfcontrol abilities. Individuals high in trait self-control - an aspect of personality thought to reflect one's ability to override temptations (Tangney, Baumeister, \& Boone, 2004) - are more likely to engage in behaviors beneficial in the long run. Higher levels of self-control are predictive of a variety of positive outcomes which require delay of gratification (Mischel, Shoda, \& Rodriguez, 1989), including better academic achievement (Duckworth \& Seligman, 2005), personal finance (Moffitt et al., 2011) and health (Crescioni et al., 2011). These effects can be long lasting. For instance, the ability to delay gratification at age 4 or 5 has been shown to be related to academic success 10 years later (Mischel et al., 1989).

Here we suggest that individuals with higher levels of trait self-control should be more adept at choosing long-term beneficial options that offset the negative effects of commuting. Higher levels of trait self-control equip individuals with the necessary psychological resources (de Ridder, Lensvelt-Mulders, Finkenauer, Stok, \& Baumeister, 2012) to use commuting time effectively for work-related tasks. This saves them time and thus reduces the time pressure and 
stress that employees experience in the office. Employees higher in trait self-control who prepare for work and thus are able to reduce the aversive impact of longer commutes should be more satisfied with their jobs (Gottholmseder et al., 2009), and be less frustrated by their commutes and so less emotionally exhausted (Cropanzano, Rupp, \& Byrne, 2003). For those with high trait self-control, we expect that job satisfaction and emotion exhaustion will not be as negatively affected by commuting time as for those with low levels of trait self-control. Thus we suggest:

Hypothesis 1: The relationship between commuting time and (a) job satisfaction and (b) emotional exhaustion is less pronounced for individuals who have high trait self-control, than for those who have low trait self-control.

Lower levels of job satisfaction make it more likely that employees want to leave the organization (Cropanzano et al., 2003; Mobley, 1977; Tett \& Meyer, 1993; Wright \& Cropanzano, 1998). Employees lower in trait self-control who will be more likely to be negatively affected by longer commutes should therefore be more likely to leave the organization that requires them to commute longer.

Hypothesis 2: The interaction between trait self-control and commuting time indirectly predicts employee turnover, through job satisfaction.

\section{The Benefits of Goal-Directed Prospection While Commuting}

A rite of transition can involve activities that prepare individuals to enter into their work roles (Ashforth et al., 2000). Employees can choose to create a mental buffer between conflicting role identities during their morning commute by engaging in future-oriented thoughts (i.e., goaldirected prospection). That is, employees could think about their upcoming day at work, their schedules, possible difficulties they are facing, and can plan ahead to best manage these different aspects of their work. This can have positive long-term effects: transitioning into work while 
commuting can help employees better deal with role conflicts, plan work more effectively, and reduce the time pressure at work. Thus, we suggest that it is specifically goal-directed prospection during commutes that increases job satisfaction and decreases emotional exhaustion at work.

Goal-directed prospections may be especially beneficial as they contain positive expectations on the basis of past successes, and thus signal that current exertions of effort are investments into the future that will pay off (Oettingen \& Mayer, 2002). This type of optimistic thinking - in contrast to engaging in positive illusions - can foster motivation for the achievement of future long-term goals. But goal-directed prospections do not need to necessarily involve positive thinking about the future in order for them to be effective on one's motivation and performance on the tasks that are thought about. Simply thinking about one's goals for the day (or the longer term) and how to achieve them is enough in producing benefits, including leading one to optimize one's time for those goals (Locke \& Latham, 2002). In fact, beyond higher motivation to succeed, engaging in goal-directed prospection can also serve to directly affect the likelihood individuals will succeed in achieving their goals. This is because prospection serves as a cue for implementation intention, a detailed plan of how the goal will be achieved (Gollwitzer, 1999). This type of planning may include planning an adequate amount of time and even incorporating planned breaks to make goal achievement more likely (Gollwitzer, Gawrilow, \& Oettingen, 2010). The mere act of planning for goal achievement also reduces the need for the exertion of further cognitive resources on unfulfilled goals (Masicampo \& Baumeister, 2011). Consistent with this possibility, Benoit and colleagues (2011) find that prospection motivates individuals to make long-run beneficially decisions in the present as it shifts emphasis from the short-term, myopic, toward the long-term (Liu, Feng, Chen, \& $\mathrm{Li}$, 
2013). Thus, we predict that goal-directed prospection helps optimize employees' goal-related activities, thereby enhancing job outcomes.

Hypothesis 3. Goal-directed prospection is (a) positively related to job satisfaction, and

(b) negatively related to emotional exhaustion.

\section{Self-Control Facilitates Goal-Directed Prospection}

Individuals higher in trait self-control are more likely to engage in planning ahead of time (Gollwitzer et al., 2010). Higher levels of trait self-control are achieved in part through a variety of approaches that often resemble behavioral strategies that influence how the temptation and the long-term goal are being perceived. For example, these include reinterpreting the meaning of the stimuli (Mischel, Ebbesen, \& Zeiss, 1972), changing the psychological distance to the temptation (Fujita \& Han, 2009), or deploying behavioral strategies in advance of potential conflicts to avoid temptations altogether (Magen \& Gross, 2010). In addition, although self-control can only be exercised once a conflict between a short-term temptation and long-term beneficial goal is identified (Myrseth \& Fishbach, 2009), people higher in trait self-control are also more adept at perceiving a potential self-control conflict (Gillebaart \& De Ridder, 2015), and might therefore avoid the conflict in the first place and thus be more likely to achieve long-term goals. Engaging in prospection reduces the rate of delay discounting - a task commonly associated with the need to exercise self-control (Liu et al., 2013). Taken together, these findings suggest that employees high in trait self-control, compared to those low in self-control, may be more likely to use commuting time not for short-term, immediately gratifying activities, but rather for goal-directed prospection, a long-term beneficial activity. Additionally, one's likelihood of engaging in goaldirected prospection can function as a mechanism by which individuals buffer the negative jobrelated consequences of lengthy commute. 
Hypothesis 4: Individuals who have high levels of trait self-control are more likely to engage in goal-directed prospection, as compared to those who have low levels of trait self-control.

Hypothesis 5: Goal-directed prospection during one's commute partially mediates the relationship between trait self-control and job outcomes.

\section{Overview of the Present Research}

Our theoretical framework is summarized in Figure 1. We test the hypotheses in three studies. The first study consists of a multisource field study in the UK offices of a large global media company. Here we investigated whether lengthy commutes have a negative relationship with job-related outcomes, and whether these outcomes are more or less pronounced for individuals with varying levels of trait self-control (thus testing Hypothesis 1a and 2). In the second study, we conducted an online survey to investigate the content of employees' thoughts during commutes using a recall task. This study allows us to examine whether employees who have high trait self-control are more likely to engage in goal-directed prospection during their commutes, as compared to those who have low trait self-control. We also show that engaging in goal-directed prospection mediates the relationship between commuting time and negative jobrelated outcomes (thus providing support for Hypotheses 1a, 1b, 3a, 3b, 4 and 5). In the third study, we directly manipulate the proposed mechanism (i.e., goal-directed prospection) by prompting employees to engage in goal-directed prospection while commuting. This study presents evidence for the causal relationship between goal-directed prospection and job-related outcomes (in support of Hypotheses 3a, 3b, and 5).

Insert Figure 1 about here 


\section{STUDY 1}

The aim of this study was to provide evidence for the differential effects of commute time on job-related outcomes on the basis of varying levels of trait self-control. In particular, the study was designed to test whether individuals with higher trait self-control were less likely to be affected by longer commutes (Hypothesis 1a and 2), both on a subjective indicator (job satisfaction) as well as an objective measure (turnover).

\section{Method}

Sample and Procedures. We conducted a field study at the UK offices of a global media company. The company's CEO sent email invitations to all employees (i.e., 559 of them) to participate in the first survey, with questions regarding trait self-control. Thirty days later, the CEO invited the employees to complete the second survey, which included questions about the employees' levels of job satisfaction. In addition, the human resources department of the company provided us with information about demographics 12 months prior to the start of the study, and turnover approximately 6 months after the second survey. No incentives for survey completion were provided and the participation in the surveys was voluntary. However, employees were informed the firm would donate $£ 1$ for each completed survey to the Somerset Flood Relief Fund (a fund managed by an independent foundation to support recovery efforts from a flood in the greater London area).

A total of 225 employees of the 559 invited employees completed both surveys and had human resources data that could be matched $\left(M_{\text {age }}=32.72, S D_{\text {age }}=6.87 ; 57 \%\right.$ male $)$. Respondents had worked, on average, for 2.85 years $(S D=3.37)$ in the firm. We compared the demographic information provided by respondents and non-respondents, and found no significant differences 
in age (NR- $M=31.97, S D=9.00, t(557)=1.24, n s$.$) , firm tenure (NR- M=3.04, S D=3.73$, $t(557)=0.54, n s$.$) , or gender (NR: N=335,35.2 \%$ female, X2(1)=3.50, ns.). Of 559 invited participants, 332 responded to the first survey (59.4\%), and 333 responded to the second survey (59.6\%); respondents did not significantly differ in age, tenure, or gender from non-respondents.

\section{Measures}

Commuting Time. Employees reported actual time taken to commute to and from work on a daily basis. Commuting time ranged from 7 to 135 minutes, with an average of 50.56 minutes $(S D=31.8)$.

Trait Self-Control. In the first survey, we measured employees' dispositional self-control using a 10-item scale (Tangney, Baumeister, \& Boone, 2004). Example items include: "I am good at resisting temptation," "People would say that I have very strong self-discipline," and "I do things that feel good in the moment but regret later on." Participants indicated the extent to which these statements describe them (1="Very much like me" to $5=$ "Not at all like me," $\alpha=0.77)$.

Job Satisfaction. In the second survey, we measured employees' job satisfaction using a 3-item scale (Morris \& Venkatesh, 2010 1=“Strongly Disagree" to 7=“Strongly Agree;" $\alpha=0.81$ ): "Overall, I am satisfied with my job," "I would prefer another, more ideal job," and "I am satisfied with the important aspects of my job."

Actual Turnover. Forty-one respondents (19.2\%) left the company during the time after the second survey, a rate that is relatively common for companies in this sector.

Control Variables. We controlled for age, gender and organizational tenure in the analyses based on Griffeth, Hom, and Gaertner (2000)'s study showing that both age and tenure were negatively related to turnover, whereas gender only had a weak relationship with turnover - 
with women quitting fewer times than men.

\section{Results}

Table 1 reports means and standard deviations for the key variables in this study, as well as their zero-order correlations. We first tested Hypothesis 1a regarding the role of trait selfcontrol in moderating the relationship between commuting time and job satisfaction. For the regression analysis, we entered job satisfaction as the outcome variable, commuting time as the independent variable, trait self-control as the moderator, and age, gender, and organizational tenure as control variables. As Table 2 shows, we found a significant interaction between commuting time and trait self-control $(p=0.019)$. The relationship between commuting time and job satisfaction was only significant for employees with low trait self-control (-1SD), $B=0.296$, $S E=0.135, p=0.03$, but not for employees with higher levels of trait self-control (+1SD), $\mathrm{B}=0.143, \mathrm{SE}=0.117, p=0.223$, as depicted in Figure 2 .

Insert Tables 1 and 2 and Figure 2 about here

Next, we tested Hypothesis 2 that suggested the positive relationship between commuting time and employee turnover outcomes through decreased job satisfaction is more pronounced for those who have low trait self-control. Using the PROCESS model 8 (Hayes, 2013), we entered commuting time as an independent variable, actual turnover in 6 months as a dependent measure, trait self-control as a moderator, job satisfaction as a mediator, and age, gender, and tenure as covariates. This model shows that when job satisfaction was entered in the logistic regression model, only job satisfaction was a significant predictor of turnover, $\mathrm{B}=0.068, S E=0.021$, $p=0.001$, while the interaction between commuting time and trait self-control is no longer a 
significant predictor of turnover (from $\mathrm{B}=0.22, S E=0.092, p=0.017$ to $\mathrm{B}=0.004, S E=0.03$, $p=0.889)$. A bootstrap analysis with 1,000 bias-corrected samples confirmed that a $95 \%$ confidence interval did not include zero for the conditional indirect effect of job satisfaction for individuals who have low trait self-control (estimate $=-0.02$, boot $S E=0.011,95 \% \mathrm{CI}=[0.004$, 0.049]). However, for those who have high trait self-control, the confidence interval included zero (estimate $=-0.01$, boot $S E=0.009,95 \% \mathrm{CI}=[-0.035,0.002])$. Finally, we repeated the same analyses without control variables, and this did not change the direction and significance of the results.

\section{Discussion}

Our results suggest that the relationship between commuting time and job satisfaction is more pronounced for individuals with low self-control, as compared to those with high selfcontrol. We also found that the relationship between commuting time and actual turnover is more pronounced for individuals with low self-control, as compared to those with high self-control. Further, job satisfaction explained the relationship between the interaction term (commuting time $\mathrm{x}$ trait self-control) and actual turnover outcomes six months after the survey was administered. This finding suggests that the negative consequences of lengthy commutes reduce job satisfaction, and as a result, this leads to higher likelihood of exit, but only for employees who have low trait self-control.

This study provided empirical support for our first hypothesis in a field setting with an objective dependent measures that are organizationally relevant (job satisfaction and actual turnover). We designed the next study to understand whether individuals with high (vs. low) selfcontrol engage in different thoughts during their commute. 


\section{STUDY 2}

In Study 2, our main goal was to identify why employees with higher trait self-control are less affected by longer commutes. Specifically, we investigated the content of thoughts employees have during their commutes. We predicted that individuals with higher trait selfcontrol would be more likely to engage in goal-directed prospection (Hypothesis 4), in turn mediating the relationship between trait self-control and work-related outcomes (Hypothesis 1a, $1 b, 3 a, 3 b$, and 5).

\section{Method}

Sample and Procedures. We recruited individuals through Amazon Mechanical Turk, an online labor market (Buhrmester, Kwang, \& Gosling, 2011). In the job posting for completing the study, we explicitly specified that this study was only available to individuals who work fulltime and commute to work. At the beginning of the survey, we then asked individuals whether they worked full-time and whether they commuted. Only individuals who replied "yes" to both questions were invited to participate in the main study. A total of 229 (71.3\% of the total 321 initial respondents) participants fit this category, which formed the sample for our survey $\left(M_{a g e}=36.41, S D_{a g e}=10.60 ; 58 \%\right.$ male $)$. Individuals were paid $\$ 1$ for their participation. We first measured trait-level self-control with a standard measure, then whether subjects engaged in goaldirected prospection with an open-ended question, and finally relevant job-related outcomes such as job satisfaction and emotional exhaustion with standard measures.

\section{Measures}

Commuting Time. Participants reported actual time taken to commute to and from work on a daily basis. Commuting time ranged from 3 to 120 minutes, with an average of 38.09 minutes $(S D=25.58)$. 
Trait Self-Control. We measured employees' dispositional self-control using the same 10-item scale from Study 1 (Tangney, Baumeister, \& Boone, 2004). Participants indicated the extent to which each item describe them on a 5-point scale $(1=$ "Very much like me" to $5=$ "Not at all like me," $\alpha=0.88)$.

Goal-directed Prospection during Commute. We asked respondents to "list all of the things you typically think about while commuting" in an open text box. Two independent coders then analyzed each response, coding for goal-directed prospection during commute $(0=$ no, $1=$ yes; IRR $=.71$ ). In a total of 45 cases (out of 229), the coders ratings did not coincide. In order to resolve these conflicts, we asked a third coder to evaluate these 45 cases to resolve the conflict. Examples of goal-directed prospection are as follows:

"I think about what I will do when I get into the office. I try to plan out what things I will accomplish for the day. I think about what I will do for lunch and what I will ultimately do when I get out of work for the day."

"If I'm on my way to work I'm usually planning my day in my head. If I have a meeting I will be holding I will be either thinking about it or practicing what I will say. If I'm on my way home I'm usually thinking about what I've accomplished for that day and planning things for the next day."

"I think about what I have to do for work that day and also think about whether I had completed all of my tasks related to the day before. I think about how I'm going to try to be organized at work and get activities done in a timely manner."

Job Satisfaction. We measured the extent to which participants were satisfied with their jobs using the same 3-item scale as in Study 1 (Morris \& Venkatesh, 2010; $\alpha=.81$ ).

Emotional Exhaustion. Since the employee turnover data were not available in this study, we measured employees' levels of emotional exhaustion using four items by Wilk and 
Moynihan (2005), based on Maslach and Jackson's (1981) Maslach Burnout Inventory.

Respondents answered the items on a four-point Likert-scale, ranging from $1=$ never to $4=$ always. The items are "I feel burned out from my work," "I feel fatigued when I get up in the morning and have to face another day on the job," "I feel frustrated by my job," and "I feel like I'm at the end of my rope. $(\alpha=.84)$ "

\section{Results}

Table 3 reports means and standard deviations for the key variables in this study, as well as their zero-order correlations. As Table 3 shows, in line with previous work, longer commutes were related to lower job satisfaction $(r=-.24, p<0.01)$ and higher emotional exhaustion $(r=$ $.23, p<0.01)$. It should also be noted that there was a main effect of trait self-control on jobrelated outcomes, whereas in Study 1, the effect of trait self-control on job satisfaction and turnover outcomes was conditional on commuting time. We suspect that this is potentially due to the fact that questions relating to self-control and commuting were asked first, which may have encouraged the employees to think about their job-related attitudes in terms of their ability to resist temptation during the commute and work hours.

We replicated the results of Study 1 using Hayes' (2015) PROCESS Model 1, whereby the interaction between commuting time and trait self-control was significant for both job satisfaction $\left(\mathrm{F}_{1,223}=4.28, p<0.05\right)$ and emotional exhaustion $\left(\mathrm{F}_{1,223}=13.03, p<0.01\right)$, thus providing support for Hypothesis 1a and 1b. As in Study 1, the negative relationship between commuting time and job satisfaction was more pronounced for individuals with low than high trait self-control.

Insert Table 3 about here 
Individuals who engaged in goal-directed prospection had higher levels of job satisfaction $(r=.15, p<.01)$ and lower levels of emotional exhaustion $(\mathrm{r}=-.18, p<.01)$, thus providing support for Hypotheses $3 \mathrm{a}$ and $3 \mathrm{~b}$. We then tested our hypothesis that individuals who are high on trait self-control are more likely to engage in goal-directed prospection during their commute (i.e., Hypothesis 4). Supporting Hypothesis 4, trait self-control was positively correlated with one's likelihood of engaging in prospection, Odds Ratio $=1.74, S E=0.38$, $p=0.012$.

Lastly, we tested Hypothesis 5 and examined whether individuals' likelihood of engaging in goal-directed prospection during commuting partially mediates the relationship between trait self-control and work-related outcomes, in this case job satisfaction and emotional exhaustion. We estimated the indirect effects with the coefficients from the full model, and then used bootstrapping to construct confidence intervals based on 1,000 random samples (James et al. 2006; Stine, 1989). The indirect effect did not include zero for both job satisfaction (estimate=0.026 , boot $S E=0.016,95 \% \mathrm{CI}=[0.001,0.09]$ ), as well as emotional exhaustion (estimate $=-0.03$, boot $S E=0.016,95 \% \mathrm{CI}=[-.086,-.027])-$ see Table 4 .

Insert Table 4 about here

As reported, we found that engaging in goal-directed prospection partially mediated the relationship between having high self-control and being satisfied at work, as well as being less emotionally exhausted at work.

\section{Discussion}


Using an open-ended question to predict a set of thoughts that people engage in, we identified goal-directed prospection during daily commute as a mediating variable that could explain why trait self-control may be relevant to both job satisfaction and emotional exhaustion. These results also indirectly support our Hypothesis 1a, $1 \mathrm{~b}$ and 4 that trait self-control may buffer negative consequences of lengthy commute, by orienting individuals to engage in goaldirected prospection.

However, we acknowledge that self-control and goal-directed prospection were measured simultaneously, which does not allow us to establish a causal relationship. In Study 3, we set out to directly manipulate the mediating variable (i.e., goal-directed prospection), thus establishing the causal chain underpinning the reported effects (Spencer, Zanna, \& Fong, 2005).

\section{STUDY 3}

In Study 3, we examined whether goal-directed prospection would make longer commutes less negative for employees in comparison to a control group in a field setting to provide external validity. We predicted that individuals in our treatment group who were prompted to engage in goal-directed prospection during commuting would be less likely to be negatively affected by their commutes (Hypotheses 3a, 3b). This study also allowed us to test whether the behavioral strategy individuals high in trait self-control use to offset longer commutes - goal-directed prospection - can be used by all individuals regardless of their levels of trait self-control (Hypothesis 5).

\section{Method}

Sample and Procedures. We recruited participants in collaboration with a UK-based B2B health and well-being platform that provides commuting benefits. Organizations and local government councils pay a recurring subscription fee, which allows their employees to earn 
reward points toward different modes of commuting, such as using public transportation, car sharing, or cycling. We sent recruitment emails to $\sim 6500$ individuals who opted-in to receive third-party communications. Five-hundred and two individuals responded with an interest in participating in the study, and thus received a link to our first survey. The first survey included questions about commuting time and trait self-control. The survey also asked individuals for their phone number so that we could contact them during our intervention.

One hundred fifty-four individuals responded to the first study and were subsequently allocated to one of two conditions $\left(M_{a g e}=39.21, S D_{a g e}=10.03 ; 33.5 \%\right.$ female $)$ : prospection versus control. Both conditions received weekly text messages on Monday at 8.30 am for 6 weeks. Following the intervention, participants were asked to fill out the second survey. A total of 67 individuals who answered the first survey responded to the second survey, for a final response rate of $42.1 \%$. Individuals were paid $£ 6$ for their participation.

Neither demographic variables ( $p=.32$ and $p=.60$ for age and gender, respectively), nor values of trait self-control $(p=.98)$ differed significantly between participants who responded to just the first survey and those who responded to both surveys $\left(M_{a g e}=38.36, S D_{a g e}=10.09 ; 35.7 \%\right.$ women).

Intervention using Text Messages. All participants who gave us their telephone numbers were randomly assigned to one of two intervention conditions: goal-directed prospection versus control. We created instructions for the goal-directed prospection based on theory behind prospection as well as written sentences we collected from commuters and coded as goaldirected prospection in Study 2. In the goal-directed prospection condition, employees were asked to engage in more goal-directed prospection through a number of prompts: "We are interested in how our employees are spending time during their commute. Many people find it 
helpful to make a plan of their work day, or week ahead and reflect on how these plans will help them achieve their long-term personal and career goals. For example, what are the strategies you have for the week to be productive? What are the personal and career goals you care the most about? You can do what you normally do during your commute (i.e., listening to music), but please set aside a few minutes to actively engage in the future reflection."

In the control condition, participants were given the following instructions: "We are interested in how our employees are spending time during their commute. Please pay close attention to what you do, and what you think about during your typical commute to work each morning. You can do what you normally do during your commute (i.e., listening to music)."

\section{Measures}

Commuting Time. We measured employee's actual time taken to commute to and from work on a daily basis in the first survey. Commuting time ranged from 3 to 120 minutes, with an average of 49.33 minutes $(S D=32.51)$.

Trait Self-Control. We measured employees' dispositional self-control in the first survey using the same 10-item scale as in our prior studies (Tangney, Baumeister, \& Boone, 2004; $\alpha=0.83)$.

Job Satisfaction. As in Study 1 and 2, we measured the extent to which employees are satisfied with their work in the second survey using a 3-item scale (Morris \& Venkatesh, 2010; $\alpha=0.82)$.

Emotional Exhaustion. As in Study 2, we measured employees' levels of emotional exhaustion in the second survey using four items by Wilk and Moynhian $(2005 ; \alpha=.79)$.

\section{Results}


Table 5 reports means and standard deviations for the key variables in this study, as well as their zero-order correlations.

Insert Table 5 about here

Hypothesis 3 predicted that goal-directed prospection would be (a) positively related to job satisfaction, and (b) negatively related to emotional exhaustion. To test this hypothesis, we grouped individuals by the type of intervention message they received, and then analyzed our data. First, we used job satisfaction as the outcome variable. As expected in Hypothesis 3a, individuals who were asked to engage in goal-directed prospection during their commutes had higher levels of job satisfaction $(M=4.8, S E=1.1)$ than those who received the control text message $(M=4.01, S E=1.58), t(65)=2.364, p=0.021$ (see Figure 3$)$. Next, we used emotional exhaustion as the outcome variable. Consistent with Hypothesis 3b, individuals who were asked to engage in goal-directed prospection during their commutes had lower levels of emotional exhaustion $(M=2.81, S E=1.07)$ than those who received the control text message $(M=3.83$, $S E=1.44), t(65)=3.28, p=0.002$.

Importantly, this pattern of results holds even when controlling for levels of trait selfcontrol, thus providing support for Hypothesis 5. In regression analyses with job outcomes as our DVs, our manipulation targeted at goal-directed prospection predicted job satisfaction $(\mathrm{B}=-2.36$, $S E=1.027, p=.025)$, while the effect of trait self-control was not significant $(\mathrm{B}=.028, S E=.074$, $p=.70)$. Similarly, condition significantly predicted emotional exhaustion $(B=3.9, S E=1.24$, $p=0.003)$, while the effect of trait self-control did not reach traditional levels of significance $(\mathrm{B}=-$ $.168, S E=.090, p=.067)$. 
Is goal-directed prospection independent of trait self-control, or do individuals with higher (lower) levels of trait self-control benefit more (less) from engaging in goal-directed prospection? Consistent with Hypothesis 5, we find that the treatment effect did not vary at different levels of trait self-control, supporting the view that the treatment effect was not additive. Regardless of participants' level of trait self-control, participants who received the goaldirected prospection intervention were more likely to be satisfied with their job and less likely to be emotionally exhausted (i.e., the interaction terms between treatment and TSC were not significant for both job satisfaction and emotional exhaustion, $p=.39$ and $p=.90$ respectively).

Insert Figure 3 about here

\section{Discussion}

This intervention field study sheds light into the causality of the relationship between goal-directed prospection and reduced negative effects of commutes. Prompting commuters to engage in goal-direct prospection while they commute every Monday morning for 6 weeks increased their job satisfaction and decreased their emotional exhaustion. A control group who was asked to pay close attention to what they do did not show these beneficial effects, alleviating concerns of a mere treatment effect. By directly manipulating the mediator in a real-world setting, we were thus able to make stronger claims about the direction of our theorized relationship.

Additionally, we find that our intervention holds true across levels of trait self-control. This suggests that engaging in goal-directed prospection is a behavior individuals with higher trait self-control are more likely to engage in, yet that this is a behavior that can be learned and 
adopted by employees regardless of their levels of trait self-control. This has important consequences for the design of future interventions to reduce negative outcomes for commuting employees.

\section{GENERAL DISCUSSION}

Does commuting always lead to negative work-related outcomes? In two field studies and an online study, we found that employees with higher levels of trait self-control are less likely to experience negative effects of longer commutes. Individuals higher in trait self-control show a weaker relationship between longer commutes and job satisfaction - also impacting their likelihood of turnover. Upon closer examination, we find that individuals with higher trait selfcontrol are more likely to engage in goal-directed prospection during commuting. Their increased propensity to engage in goal-directed prospection during commuting partially explains why they are able to offset negative effects of longer commutes better. The beneficial effects of goal-directed prospection during commuting are however not limited to individuals with higher levels of trait self-control; goal-directed prospection is thus a behavioral strategy individuals can use independent of their levels of trait self-control. Indeed, individuals prompted to engage in goal-directed prospection during commuting show higher job satisfaction and lower emotional exhaustion - even when controlling for trait self-control. Our findings offer meaningful theoretical contributions to the literatures on commuting, boundary work and recovery work.

\section{Theoretical Contribution}

Our research contributes to the management literature in several ways. Our primary contribution lies in a closer investigation of the relationship between commuting and workrelated outcomes. To date, the literature has primarily treated commuting as an annoying aspect of work to be avoided or at least minimized (Stutzer \& Frey, 2008). The negative impact of 
commuting can prove even worse for employees as they often underestimate its impact and so inaccurately factor in commuting effects in their decision-making process (Stutzer \& Frey, 2008). We build upon Kluger's (1998) observation that some individuals seem to view commuting as an opportunity to think, rather than a chore to endure, and identify the individuallevel factor that may modulate how daily commutes influence job-related outcomes: trait selfcontrol. Even though a majority of employees view commuting mainly as a source of frustration (Kahneman \& Krueger, 2006), we conceptualize commutes as a self-control trade-off between aspects that are intrinsically gratifying, such as listening to music or reading a book, and options that are perhaps short-term aversive but long-term useful, such as engaging in goal-directed prospection. Because individuals higher in trait self-control are more likely to consistently choose the long-term over the short-term options, we argued - and found - that they are also more likely to engage in goal-directed prospection during their morning commute. Individuals may choose to extend their non-work time by engaging in activities that are non-work related but intrinsically gratifying. But individuals who view their commute as an opportunity to engage in goal-directed prospection may have benefits that extend beyond a single work day, thereby reducing emotional exhaustion and increasing job satisfaction in the long-term.

Our research also identifies how individuals higher in trait self-control manage to offset the negative effects of longer commutes. Taking a moment to reflect on what they would like to achieve in the future and making plans accordingly can carry over to how they engage and execute their work following their commutes. Previous work has highlighted the benefits of positive expectations and optimistic thinking, as they can foster motivation for the achievement for their long-term goal (Oettingen \& Mayer, 2002), which can in turn help remind employees that the effort they are investing at work will pay off in the future. Goal-directed prospection can 
also serve to increase the likelihood employees will achieve their goals by serving as implementation intentions (Gollwitzer, 1999). Achieving more goals can reduce the amount of unfulfilled goals, which can additionally drain cognitive resources, thus imposing a strain on employees (Masicampo \& Baumeister, 2011). By showing that engaging in specific thoughts can offset the negative effects of commuting - independently of trait self-control - we challenge the widespread notion that commuting is always negative, and provide a mechanism of how the negative effect can be reduced or even eliminated.

Our research also advances extant theory of boundary work that conceptualized commuting as a critical work-home transition. When the boundary between the two domains of work and home are weakened, work seeps into home, and home seeps into work. This can have negative consequences, such as when there is conflict between the demands of work and home (Small \& Riley, 1990), or when employees are trying to balance competing roles (Mennino et al., 2005; Schieman et al., 2003). To prevent these negative effects from occurring, employees can strengthen their boundaries, thus making the demarcation between work and home clear - with positive outcomes, such as increased job satisfaction and lower burnout (Bulger et al., 2007). Although prior research has theorized the possibility of employees engaging in either segmentation (e.g., separation of work and non-work roles) or integration (overlap between work and non-work time; Nippert-Eng, 1996), it has remained silent on a specific type of boundary work that employees could engage in during their non-work to work transition that could facilitate their role transition and thus influencing job outcomes.

Our research thus suggests that commuting to work is an ideal time period for boundary work to occur because it is a unique time period when employees are neither at work, nor at home both temporally and spatially - it stands in the middle between work and home and can 
therefore be thought of as more than an extension of work or non-work leisure time. When employees commute to work, they have a higher degree of role segmentation, and can therefore use commuting as a rite of passage, facilitating movement from one role to the other (Ashforth et al., 2000; Richter, 1990). Morning commutes in particular provide a unique opportunity to provide a buffer between distinctive role identities, as it meets Van Gennep's (1960) criteria for rites of passage: it facilitates role exit (leaving home), psychological and physical movement (transport from home to work), and role entry (arriving at work). Our findings around goaldirected prospection as boundary work suggests that such integration of work and non-work identities could indeed provide flexibility around how employees plan their day ahead, and enable them to cope with the multiple demands in their lives (Ashforth et al., 2000; Rothbard, Phillips, \& Dumas, 2005).

Finally, our work further supports research that views work-related outcomes as being affected by not just what happens at work, but also by what happens outside of work. What happens outside of work is not only the source of negative spillovers, but can also be the source of positive spillovers. A wealth of research, especially in the field of work recovery, has investigated how what employees do during (Trougakos, Hideg, Cheng, \& Beal, 2014; Trougakos \& Hideg, 2009) or after work can impact employees (Lanaj, Johnson, \& Barnes, 2014; Sonnentag, 2001, 2003, 2012). However, our research suggests that the time period before work can help reduce emotional exhaustion, which could spill over to the work day, and thus enabling employees to have higher levels of baseline energy and resources. We thus extend previous research on work recovery by arguing that engaging in goal-directed prospection prior to work can have important consequences for employees, and suggest a possibility that it could be used to effectively plan other work recovery-related activities during and after the work day. 


\section{Limitations and Future Directions}

Our studies are subject to a number of limitations that suggest directions for future research. In all of the studies, we focused our measures on the usual content of individual's commutes and we did not examine within-individual variation in commuting activities. We also did not measure daily energy directly, but only assume its impact on emotional exhaustion. Other research in work recovery literatures emphasizes the role of energy levels, especially as it affect's employee performance (Dutton, 2003). Because the beneficial effects of recovery activities fade over time (Fritz, Lam, \& Spreitzer, 2011), it would be interesting to investigate more closely how goal-directed prospection influences daily energy levels (Demerouti, Bakker, Sonnentag, \& Fullagar, 2012; Sonnentag, 2001), and to examine whether energy varies with the extent to which people engage in goal-directed prospection as compared to other activities such as listening to music. Furthermore, Matthews and Barnes-Farrell (2004) differentiate between the situational ability to engage in boundary work ('flexibility-ability') and an individual difference that captures the motivation to engage in boundary work ('flexibility-willingness'). It is unclear whether goal-directed prospection serves to increase the ability to engage in boundary work, or whether it heightens individuals' motivation to engage in boundary work, which future work could differentiate.

Throughout the studies, we focused the investigation on morning commutes. Although the theoretical conceptualization does not differ substantially for commutes after work, we may not be able to generalize the findings to the evening commute, or other work breaks, for a number of reasons: First, it is unclear whether engaging in goal-directed prospection can facilitate role entry from a work role into a non-work role the same way as it does from a nonwork role into a work role. Goal-directed prospection may only serve to strengthen boundary 
work unilaterally, but not bilaterally. Evening commutes might benefit from goal-directed prospection for activities in private life, or from reflection of the workday. Second, time spent engaging in goal-directed prospection may not have linear returns. Note that participants in the intervention condition in Study 3 were explicitly asked to continue engaging in other activities during commuting as they usually do, but to set aside a few minutes for goal-directed prospection.

The findings identify an additional specific behavioral 'signature' that specifies what individuals with higher trait self-control do in order to consistently be more likely to choose the long-term option. Although individuals are generally good at estimating their levels of trait selfcontrol - self-reported measurements converge with other behavioral measures and predict longterm outcomes (de Ridder et al., 2012) - it is unclear whether individuals with higher levels of trait self-control are aware of their ability to endure longer commutes with less negative consequences. When choosing between jobs, employees must often weigh off the benefits of living further away from work (e.g., lower rent, larger apartments, better school districts). If individuals with higher trait self-control are more adept at perceiving a potential self-control conflict (Gillebaart \& De Ridder, 2015), does that mean employees with higher trait self-control also consciously choose longer commutes? Even though in the data, we find no correlation between commuting time and trait self-control, future work should explore this area further.

\section{Practical Implications and Conclusion}

Our research offers valuable practical insights for both leaders and employees. For leaders, our studies have two key implications. First, our findings alert leaders that their employees might be differently affected by the length of their commutes. When employees have lower levels of trait self-control, they are at higher risk of being less satisfied and more 
emotionally exhausted. The popular press is quick to warn employees that long commute have negative consequences, but some employees may stand to gain more from the benefits of living further away from work by offsetting the negative effects of commuting. Leaders need to be aware of how commutes affect their employees, and can help manage especially draining commutes for employees with lower trait self-control, either by supporting their goal-directed prospection during commuting, or suggesting other ways to reduce commuting time, such as increased teleworking.

Second, our work highlights leaders need to take a more holistic conceptualization of their employees. How employees feel about their work, and how well they perform, is not just a function of what employees do at work, but also of what employees do outside of work. This is especially important in the facilitation of the establishment of clear boundaries between work and home. Leaders can help their employees by supporting the development of clear boundaries between work and home, either through 'hard' changes - such as switching off email servers after working hours to ensure employees have the opportunity to recover adequately - or through 'soft' suggestions, such as encouraging goal-direct prospection during morning commutes.

For employees, our findings highlight that although to some extent commuting time may be outside their control, they are nonetheless in charge of their commute. Commuting is not per se a chore to endure, but can also be viewed as a useful time period. Being able to set aside a few minutes during commuting for prospection can turn a time period that many employees rate as their least desirable into a slightly less aversive time period - or at least a much more beneficial one. Furthermore, our research highlights the need to consider boundaries between work and home. Engaging in goal-directed prospection while commuting - where employees are neither at work, nor at home - is a type of boundary work that can improve work-related outcomes. 


\section{REFERENCES}

Ashforth, B. E., Kreiner, G. E., \& Fugate, M. 2000. All in a Day's Work: Boundaries and Micro Role Transitions. Academy of Management Review, 25(3): 472-491.

Baumeister, R. F., Bratslavsky, E., Muraven, M., \& Tice, D. M. 1998. Ego depletion: is the active self a limited resource? Journal of Personality and Social Psychology, 74(5): 12521265.

BBC. 2015. Travelling to work "is work", European court rules.

Benoit, R. G., Gilbert, S. J., \& Burgess, P. W. 2011. A Neural Mechanism Mediating the Impact of Episodic Prospection on Farsighted Decisions. The Journal of Neuroscience, 31(18): 6771-6779.

Buhrmester, M., Kwang, T., \& Gosling, S. D. 2011. Amazon's Mechanical Turk: A New Source of Inexpensive, Yet High-Quality, Data? Perspectives on Psychological Science, 6(1): 3-5.

Bulger, C. A., Matthews, R. A., \& Hoffman, M. E. 2007. Work and personal life boundary management: Boundary strength, work/personal life balance, and the segmentationintegration continuum. Journal of Occupational Health Psychology, 12(4): 365-375.

Crescioni, W., Ehrlinger, J., Alquist, J. L., Conlon, K. E., Baumeister, R. F., Schatschneider, C., et al. 2011. High trait self-control predicts positive health behaviors and success in weight loss. Journal of Health Psychology, 16(5): 750-759.

Cropanzano, R., Rupp, D. E., \& Byrne, Z. S. 2003. The Relationship of Emotional Exhaustion to Work Attitudes, Job Performance, and Organizational Citizenship Behaviors. Journal of Applied Psychology, 88(1): 160-169.

de Ridder, D. T. D., Lensvelt-Mulders, G., Finkenauer, C., Stok, F. M., \& Baumeister, R. F. 2012. Taking stock of self-control: a meta-analysis of how trait self-control relates to a wide range of behaviors. Personality and Social Psychology Review, 16(1): 76-99.

Demerouti, E., Bakker, A. B., Sonnentag, S., \& Fullagar, C. J. 2012. Work-related flow and energy at work and at home: A study on the role of daily recovery. Journal of Organizational Behaviour, 33: 276-295.

Duckworth, A. L., \& Seligman, M. E. P. 2005. Self-discipline outdoes IQ in predicting academic performance of adolescents. Psychological Science, 16(12): 939-944.

Dutton, J. E. 2003. Energize your workplace: How to create and sustain high-quality connections at work. San Francisco, CA: Jossey-Bass.

Fox, M. L., Dwyer, D. J., \& Ganster, D. C. 1993. Effects Of Stressful Job Demands And Control 
On Physiological And Attitudinal Outcomes In A Hospital Setting. Academy of Management Journal, 36(2): 289-318.

Fritz, C., Lam, C. F., \& Spreitzer, G. M. 2011. It's the Little Things That Matter: An Examination of Knowledge Workers' Energy Management. Academy of Management Perspectives, 25(3): 28-39.

Fujita, K., \& Han, H. A. 2009. Moving beyond deliberative control of impulses: the effect of construal levels on evaluative associations in self-control conflicts. Psychological Science, 20(7): 799-804.

Gaines, J., \& Jermier, J. M. 1983. Emotional Exhaustion in a High Stress Organization. Academy of Management Journal, 26(4): 567-586.

Gillebaart, M., \& De Ridder, D. T. D. 2015. Effortless Self-Control: A Novel Perspective on Response Conflict Strategies in Trait Self-Control. Social and Personality Psychology Compass, 2(10): 88-99.

Gollwitzer, P. M. 1999. Implementation intentions: Strong effects of simple plans. The American Psychologist, 7: 493-503.

Gollwitzer, P. M., Gawrilow, C., \& Oettingen, G. 2010. The Power of Planning: Self-Control by Effective Goal-striving. Self-Control in Society, Mind, and Brain: 279-296. New York: Oxford University Press.

Gottholmseder, G., Nowotny, K., Pruckner, G. J., \& Theurl, E. 2009. Stress perception and commuting. Health Economics, 18(5): 559-76.

Hall, D. T. 1990. Telecommuting and the management of work-home boundaries. Paradigms revised: The annual review of communications in society-1988: 177-208. Nashville, TN: Institute for Information Studies.

Hofmann, W., Luhmann, M., Fisher, R. R., Vohs, K. D., \& Baumeister, R. F. 2014. Yes, But Are They Happy? Effects of Trait Self-Control on Affective Well-Being and Life Satisfaction. Journal of Personality, 82(4): 265-277.

Kahneman, D., \& Krueger, A. B. 2006. Developments in the Measurement of Subjective WellBeing. Journal of Economic Perspectives, 20(1): 3-24.

Kluger, A. N. 1998. Commute variability and strain. Journal of Organizational Behavior, 19: 147-165.

Kneebone, E., \& Holmes, N. 2015. The growing distance between people and jobs in metropolitan America.

http://www.brookings.edu/ /media/research/files/reports/2015/03/24-jobproximity/srvy_jobsproximity.pdf, Washington, DC. 
Lanaj, K., Johnson, R. E., \& Barnes, C. M. 2014. Beginning the Workday Already Depleted? Conseqeuences of Late-Night Smartphone Use and Sleep. Management Science, 124(1): 11-23.

Leigh, J., \& Lust, J. 1988. Determinants of Emplyee Productivity. Work and Occupations, 15(1): 78-95.

Liu, L., Feng, T., Chen, J., \& Li, H. 2013. The value of emotion: How does episodic prospection modulate delay discounting? PLoS ONE, 8(11): e81717.

Locke, E. A., \& Latham, G. P. 2002. Building a practically useful theory of goal setting and task motivation: A 35-year odyssey. American Psychologist, 57(9): 705-720.

Magen, E., \& Gross, J. J. 2010. Getting Our Act Together: Toward a General Model of SelfControl. In R. Hassin, K. N. Ochsner, \& Y. Trope (Eds.), Self-Control in Society, Mind, and Brain: 335-353. New York, NY: Oxford University Press.

Masicampo, E. J., \& Baumeister, R. F. 2011. Consider it done! Plan making can eliminate the cognitive effects of unfulfilled goals. Journal of Personality and Social Psychology, 101(4): 667-683.

Matthews, R. A., \& Barnes-Farrell, J. L. 2004. Development of a comprehensive measure of boundary strength for work and family domains. Annual Meeting of the Academy of Management. New Orleans, LA.

Mennino, S. F., Rubin, B., \& Brayfield, A. 2005. Home-to-Job And Job-to-Home Spillover: The Impact of Company Policies and Workplace Culture. The Sociological Quarterly, 46(1): 107-135.

Metcalfe, J., \& Mischel, W. 1999. A hot/cool-system analysis of delay of gratification: Dynamics of willpower. Psychological Review, 106(1): 3-19.

Mischel, W., Ebbesen, E. B., \& Raskoff Zeiss, A. 1972. Cognitive and attentional mechanisms in delay of gratification. Journal of Personality and Social Psychology, 21(2): 204-218.

Mischel, W., Shoda, Y., \& Rodriguez, M. 1989. Delay of gratification in children. Science, 244(4907): 933-938.

Mobley, W. H. 1977. Intermediate Linkages in the Relationship Between Job Satisfaction and Employee Turnover. Journal of Applied Psychology, 62(2): 237-240.

Moffitt, T. E., Arseneault, L., Belsky, D., Dickson, N., Hancox, R. J., Harrington, H., et al. 2011. A gradient of childhood self-control predicts health, wealth, and public safety. Proceedings of the National Academy of Sciences of the United States of America, 108(7): 2693-8.

Myrseth, K. O. R., \& Fishbach, A. 2009. Self-Control: A Function of Knowing When and How 
to Exercise Restraint. Current Directions in Psychological Science, 18(4): 247-252.

Nippert-Eng, C. 1996. Calendars and keys: The classification of "home" and "work."

Sociological Forum, 11(3): 563-582.

Novaco, R. W., Stokols, D., \& Milanesi, L. 1990. Objective and Subjective Dimensions Of Travel Impedance as Determinants Of Commuting and Stress. American Journal of Community Psychology, 18(2): 231-257.

OECD. 2014. Average annual hours actually worked per worker.

Oettingen, G., \& Mayer, D. 2002. The motivating function of thinking about the future: expectations versus fantasies. Journal of Personality and Social Psychology, 83(5): 11981212.

Olsson, L. E., Gärling, T., Ettema, D., Friman, M., \& Fujii, S. 2013. Happiness and Satisfaction with Work Commute. Social Indicators Research, 111(1): 255-263.

Packard, J. S., \& Motowidlo, S. J. 1987. Subjective stress, job satisfaction, and job performance of hospital nurses. Research in Nursing \& Health, 10(4): 253-261.

Rampell, C. 2011, October 14. World of Commuters. The New York Times. http://economix.blogs.nytimes.com/2011/10/14/world-of-commuters/?_r=0, New York City, NY.

Richter, J. 1990. Crossing boundaries between professional and private life. The Experience and Meaning of Work in Women's Lives, 143-163.

Rothbard, N. P., Phillips, K. W., \& Dumas, T. L. 2005. Managing Multiple Roles: Work-Family Policies and Individuals? Desires for Segmentation. Organization Science, 16(3): 243-258.

Sandow, E. 2014. Til Work Do Us Part: The Social Fallacy of Long-distance Commuting. Urban Studies, 51(3): 526-543.

Schieman, S., McBrier, D. B., \& Gundy, K. Van. 2003. Home-to-Work Conflict, Work Qualities, and Emotional Distress. Sociological Forum, 18(1): 137-164.

Schmeichel, B. J., \& Zell, A. 2007. Trait self-control predicts performance on behavioral tests of self-control. Journal of Personality, 75(4): 743-756.

Small, S., \& Riley, D. 1990. Toward a Multidimensional Assessment of Work Spillover into Family Life. Journal of Marriage and the Family, 52(1): 51-61.

Sonnentag, S. 2001. Work, Recovery Activities, and Individual Well-Being: A Diary Study. Journal of Occupational Health Psychology, 6(3): 196-210.

Sonnentag, S. 2003. Recovery, Work Engagement, and Proactive Behaviour: A New Look at the 
Interface between Nonwork and Work. Journal of Applied Psychology, 88(3): 518-528.

Sonnentag, S. 2012. Psychological Detachment From Work During Leisure Time: The Benefits of Mentally Disengaging From Work. Current Directions in Psychological Science, 21(2): $114-118$.

Spencer, S. J., Zanna, M. P., \& Fong, G. T. 2005. Establishing a Causal Chain: Why Experiments are Often More Effective than Mediational Analysis in Examining Psychological Processes. Journal of Personality and Social Psychology, 89(6): 845-851.

Stutzer, A., \& Frey, B. S. 2008. Stress that doesn't pay: The commuting paradox. Scandinavian Journal of Economics, 110(2): 339-366.

Tangney, J. P., Baumeister, R. F., \& Boone, A. L. 2004. High Self-Control Predicts Good Adjustment, Less Pathology, Better Grades, and Interpersonal Success. Journal of Personality, 72(2): 271-324.

Tett, R. P., \& Meyer, J. P. 1993. Job Satisfaction, Organizational Commitment, Turnover Intention, and Turnover: Path Analyses Based on Meta-Analytic Findings. Personnel Psychology, 46(2): 259-293.

Trougakos, J. P., \& Hideg, I. 2009. Momentary work recovery: The role of within-day work breaks. Current Perspectives on Job-Stress Recovery, Research in Organisational Stress and Well Being, 7: 37-84.

Trougakos, J. P., Hideg, I., Cheng, B., \& Beal, D. 2014. Lunch breaks unpacked: the role of autonomy as a moderator of recovery during lunch. Academy of Management Journal, 57(2): 405-421.

van Gennep, A. 1960. The Rites of Passage. Chicago, IL: Chicago University Press.

Van Ommeren, J. N., \& Gutierrez-i-Puigarnau, E. 2011. Are workers with a long commute less productive? An empirical analysis of absenteeism. Regional Science and Urban Economics, 41(1): 1-8.

Wilk, S. L., \& Moynihan, L. M. 2005. Display Rule "Regulators": The Relationship Between Supervisors and Worker Emotional Exhaustion. Journal of Applied Psychology, 90(5): 917-927.

Wright, T. A., \& Cropanzano, R. 1998. Emotional exhaustion as a predictor of job performance and voluntary turnover. Journal of Applied Psychology, 83(3): 486-493.

Yalof, I. 1988. Life and death: The story of a hospital. New York: Fawcett Crest. 
FIGURE 1

\section{Theoretical Framework}

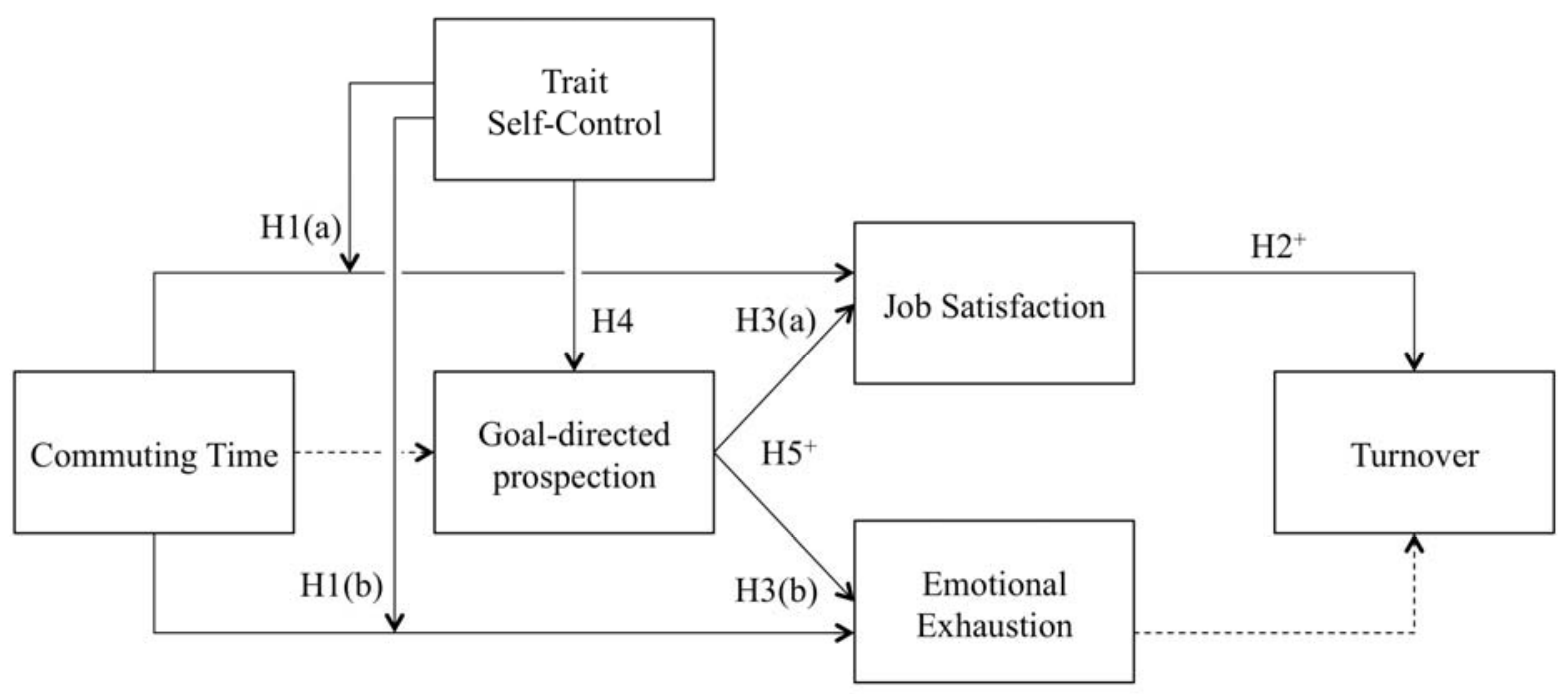

Note. Dashed lines are not tested. ${ }^{+}$indicates an indirect effect. 


\section{FIGURE 2}

Study 1: Relationship between Commuting Time and Job Satisfaction as a Function of SelfControl

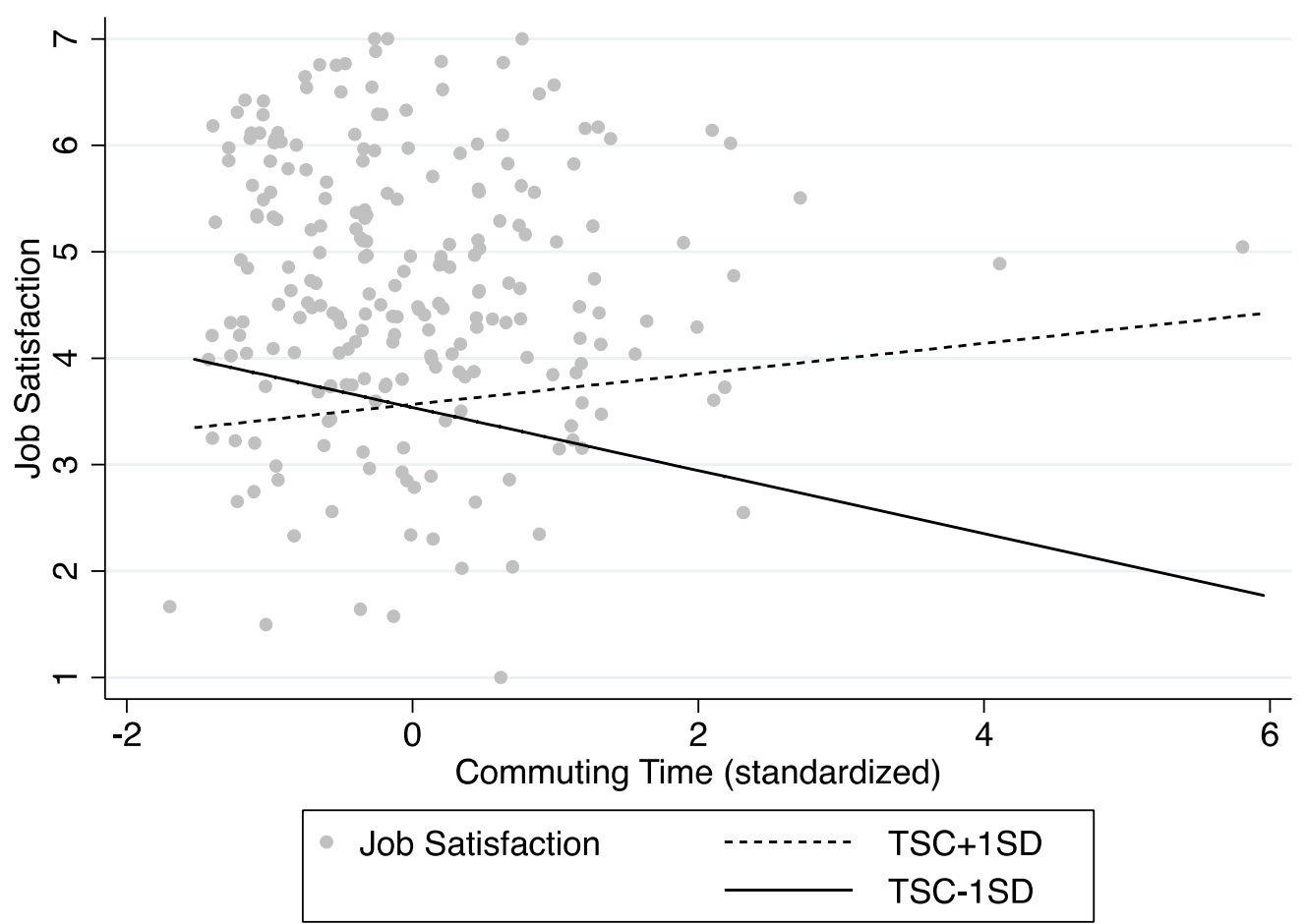

Note. TSC is short for Trait Self-Control. 


\section{FIGURE 3}

\section{Study 3: Effects of Goal-directed Prospection on Job Satisfaction and Emotional Exhaustion}
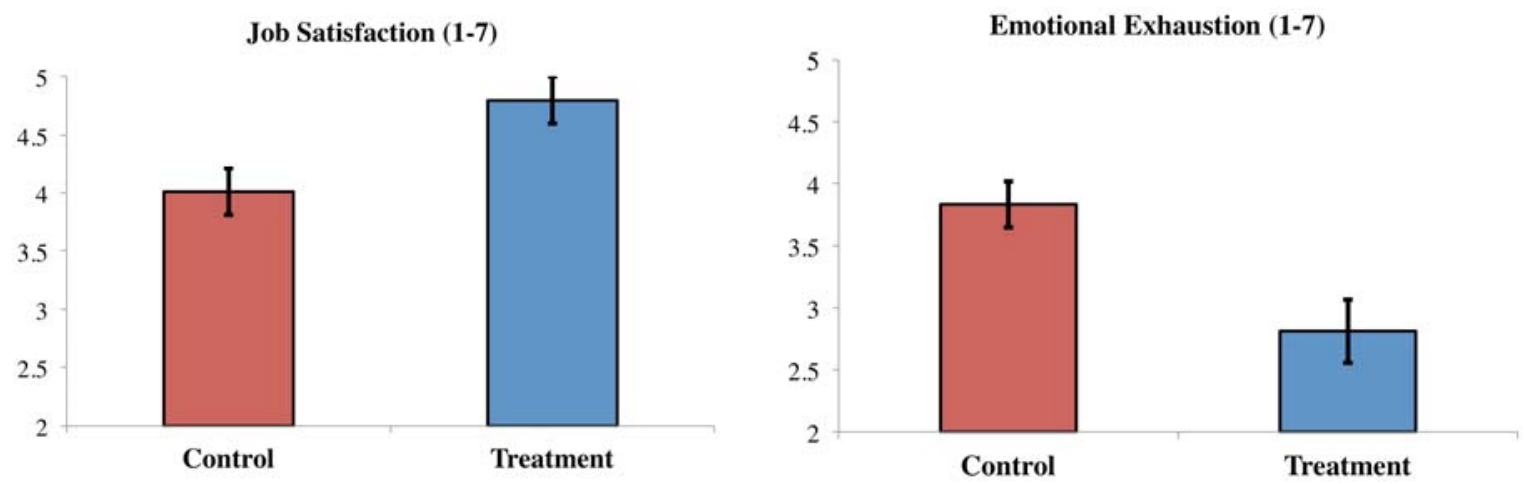

Note. In the treatment group, participants received a text message prompting goal-directed prospection. In the control group, participants received a text message asking them to pay attention to what they usually do. 
TABLE 1

Study 1: Means, Standard Deviations, and Zero-order Correlations for Key Variables

\begin{tabular}{lllllllll}
\hline & Mean & SD & 1 & 2 & 3 & 4 & 5 & 6 \\
\hline \hline Commuting Time $^{\mathrm{a}}$ & 50.60 & 31.8 & & & & & & \\
Trait Self-Control & 3.42 & .60 & .11 & & & & & \\
Age & 32.70 & 6.9 & $.18^{* *}$ & $.19^{* *}$ & & & & \\
Gender $^{\mathrm{b}}$ & .43 & .50 & -.13 & .02 & $-.14^{*}$ & & & \\
Tenure $^{\mathrm{c}}$ & 2.85 & 3.4 & $.28^{* * *}$ & $.22^{* *}$ & $.43^{* * *}$ & $-.15^{*}$ & & \\
Job Satisfaction $^{\text {Actual Turnover }}$ & 4.66 & 1.2 & -.03 & .02 & $.14^{*}$ & .05 & .00 & \\
\hline
\end{tabular}

Note. ${ }^{\mathrm{a}}$ in minutes; ${ }^{\mathrm{b}}$ gender was coded $1=$ male, $0=$ female $;{ }^{\mathrm{c}}$ in months; ${ }^{* * *} p<0.001,{ }^{* *} p<0.01$, $* p<0.05$. 
TABLE 2

Study 1: Moderated Regression Analysis

\begin{tabular}{lcc}
\hline Predictor Variables & \multicolumn{2}{c}{ Job Satisfaction } \\
\hline \multirow{2}{*}{ Age } & $\mathrm{B}$ & $S E$ \\
Gender $^{\mathrm{a}}$ & $.03 *$ & .01 \\
Tenure $^{\mathrm{b}}$ & .16 & .17 \\
Commuting Time $^{\mathrm{c}}$ & -.03 & .03 \\
Trait Self-Control $_{\text {Interaction (Time x Self-Control) }}$ & -.08 & .09 \\
& .02 & .08 \\
$N$ & $.22^{*}$ & .09 \\
$F$ & & \\
$R^{2}$ & \multicolumn{2}{c}{225} \\
\hline
\end{tabular}

Note. ${ }^{a}$ gender was coded $1=$ male, $0=$ female; ${ }^{\mathrm{b}}$ in months; ${ }^{\mathrm{c}}$ in minutes; ${ }^{*} p<0.05$. 
TABLE 3

Study 2: Means, Standard Deviations, and Zero-order Correlations for Key Variables

\begin{tabular}{lllllllll}
\hline & Mean & SD & 1 & 2 & 3 & 4 & 5 & 6 \\
\hline \hline Commuting Time $^{\mathrm{a}}$ & 38.04 & 25.6 & & & & & & \\
Trait Self-Control & 3.50 & .82 & $-.18^{* *}$ & & & & & \\
Goal-Directed Prospection & .67 & .47 & -.03 & $.19^{* *}$ & & & & \\
Job Satisfaction & 4.57 & 1.38 & $-.24^{* * *}$ & $.20^{* *}$ & $.15^{* *}$ & & & \\
Emotional Exhaustion & 2.70 & 1.04 & $.23^{* *}$ & $-.26^{* *}$ & $-.18^{* *}$ & $-.71^{* *}$ & & \\
Gender & 1.40 & .49 & .08 & .06 & .10 & .08 & -.08 & \\
Year of Birth & 1979 & 10.6 & .04 & $-.21^{* *}$ & $-.11^{*}$ & -.03 & .11 & $-.19^{* *}$ \\
\hline
\end{tabular}

Note. ${ }^{\mathrm{a}}$ in minutes; ${ }^{\mathrm{b}}$ gender was coded $1=$ male, $0=$ female; ${ }^{* * *} p<0.001,{ }^{*} p<0.01,{ }^{*} p<0.05$ 
TABLE 4

Study 2: Mediation Analyses

\begin{tabular}{lcccccc}
\hline Path & \multicolumn{3}{c}{ Job Satisfaction } & \multicolumn{3}{c}{ Emotional Exhaustion } \\
\hline & Effect & SE & CI & Effect & SE & CI \\
Path B (Prospection --> DV) & .336 & .189 & & -.296 & .142 & \\
Path C (Total Effect) & .269 & .109 & & -.227 & .081 & \\
Path C' (Direct Effect) & .232 & .110 & & -.197 & .084 & \\
& & & & & & \\
Total Indirect Effect & $\mathbf{. 0 2 6}$ & .016 & $.001, .09$ & -.03 & .016 & $-.086,-.027$ \\
\hline
\end{tabular}

Note. CI refers to the bias-corrected $95 \%$ confidence interval; effect refers to the effect estimate using 1,000 bootstrap samples; estimates with CIs that do not include zero are statistically significant and bolded. 
TABLE 5

Study 3: Means, Standard Deviations, and Zero-order Correlations for Key Variables

\begin{tabular}{lllllll}
\hline & Mean & SD & 1 & 2 & 3 & 4 \\
\hline \hline Condition (1=treatment, 2=control) $^{2}$ & 1.50 & .5 & & & & \\
Commuting Time $^{\mathrm{a}}$ & 49.32 & 32.5 & .08 & & & \\
Trait Self-Control & 3.17 & .69 & -.10 & .16 & & \\
Job Satisfaction & 4.40 & 1.41 & $-.28^{*}$ & .00 & .07 & \\
Emotional Exhaustion & 3.33 & 1.36 & $.38^{* *}$ & -.02 & $-.25^{*}$ & $-.59^{* * *}$ \\
\hline
\end{tabular}

Note. ${ }^{a}$ in minutes; ${ }^{* * *} p<0.001,{ }^{* *} p<0.01,{ }^{*} p<0.05$ 